\title{
Siete tesis en torno al texto escolar como artefacto cultural
}

\author{
Luis Ajagan Lester (D) \\ Carlos Muñoz Labraña" (D
}

\section{RESUMEN}

Este artículo analiza los rasgos centrales que caracterizan al texto escolar en cuanto artefacto cultural. El análisis interseca las nociones semióticas de Lotman y Bakhtin, con la revisión de textos de diversos contextos. El objetivo principal de la investigación fue indagar sobre cómo el texto escolar participa en la generación de la cultura, construyendo identidades nacionales, delimitando quienes son ajenos a nuestro espacio cultural, creando ideologías y mentalidades, imponiendo significados. El estudio muestra que la recepción activa de los agentes sociales involucrados en la decodificación puede crear nuevos significados, distintos a los de los textos oficiales y que la generación de mensajes y códigos debe ser vista dialécticamente.

PALABRAS CLAVE

texto escolar; cultura; ideología; mentalidades; semiótica.

'Instituto Mexicano de Estudios Pedagógicos, Jalisco, México.

"Universidad de Concepción, Concepción, Región del Biobío, Chile. 


\section{SEVEN THESES ON TEXTBOOKS AS A CULTURAL ARTIFACT}

\section{ABSTRACT}

This article analyzes the main features that characterize the textbook as a cultural artifact. The semiotic analysis intersects notions of Lotman and Bakhtin, with a review of different contexts. The main objective of the research was to investigate how the textbook participates in the generation of culture, building national identities, defining who are foreign to our cultural space, creating ideologies and mentalities and imposing meanings. The study shows that the active reception of the social agents involved in decoding can create new meanings, different from official texts and that generating messages and codes should be viewed dialectically.

\section{KEYWORDS}

school textbooks; culture; ideology; mentalities; semiotic.

\section{SETE TESES SOBRE O TEXTO ESCOLAR COMO ARTEFATO CULTURAL}

RESUMO

Este artigo analisa os traços centrais que caracterizam o texto escolar como artefato cultural. A análise cruza as noções semióticas de Lotman e Bakhtin com a revisão de textos de diversos contextos. O objetivo principal da pesquisa foi indagar sobre como o texto escolar participa da geração da cultura, construindo identidades nacionais, delimitando aqueles que são estranhos a nosso espaço cultural, criando ideologias e mentalidades, impondo significados. O estudo mostra que a recepção ativa dos agentes sociais envolvidos na decodificação pode criar novos significados, diferentes dos textos oficiais, e que a geração de mensagens e códigos deve ser vista dialeticamente.

PALAVRAS-CHAVE

texto escolar; cultura; ideologia; mentalidades; semiótica. 


\section{INTRODUCCIÓN}

El texto escolar es un texto didáctico que se utiliza en situaciones de enseñanza y así ha sido entendido desde su creación. Pero también es un texto que participa en la construcción y recreación de la cultura. Es, por consiguiente, además de un texto que se emplea en situaciones explícitamente pedagógicas, un texto de cultura. El objetivo de este trabajo es discutir desde una perspectiva que tiene su origen en las concepciones semióticas sobre la cultura de Lotman $(1999,1990)$ y de Bakhtin (1991,1987), el rol del texto escolar en la creación de un espacio existencial interno (el nosotros que constituye a cada grupo étnico, de clase, de sexo o de género) y los espacios externos a la cultura (ellos, los que no pertenecen a nuestro espacio cultural). Pretendemos, además, indagar en las características de los procesos de generación de puntos de referencia culturales que formulan y proponen los textos escolares y en la participación de dichos textos en la reproducción y creación de ideologías y mentalidades.

Nos interesa ver cómo el texto escolar contribuye a la producción y reproducción de la semiosfera - espacio semiótico que hace posible la comunicación - aquel espacio que crea las normas de comunicación, de intercambio - y de la semiosis. Nada válido comunicativamente existe fuera de la semiosfera, afirma rotundamente Lotman (1990, p. 123-130; 1999, p. 24). El texto escolar contribuye activa y poderosamente a reproducir la semiosfera. Por medio de textos escolares se enseña la lengua materna, se dan a conocer y se aprenden los símbolos patrios, se desarrolla el culto a los héroes, $\mathrm{y}$ - como desarrollaremos más adelante — se aprende también a conocer a los enemigos. El texto escolar está impregnado de ideologías y de mentalidades, ingredientes propios de la semiosfera y no tan solo de conocimientos neutrales, indiscutibles, producto de la elaboración de técnicos también neutrales.

$\mathrm{El}$ análisis del texto escolar, desde la perspectiva que hemos enunciado, se extiende mucho más allá de la visión estrechamente técnica. Esto porque dicha mirada tiende a reducir el análisis de los libros escolares a cuantificar: el largo de los párrafos, a contabilizar la frecuencia de uso de ciertos términos, verificar si hay o no explicaciones, constatar cuán complejo o simple es el vocabulario elegido y si está adaptado o no a las edades del grupo que será receptor, etc.

No se trata de menospreciar las variables enumeradas, sino de señalar que todas ellas podrían estar presentes. Por consiguiente, desde esta perspectiva un texto puede ser bien evaluado, pero, sus mensajes pueden ser o bien clasistas o bien sexistas o expresar diversos sesgos, por ejemplo, coadyuvar a consolidar una mentalidad de superioridad respecto de otros pueblos. Esta paradoja es, a nuestro entender, producto de la desconsideración de lo que señalaban los integrantes del círculo de Bakhtin en cuanto a que forma y contenido son inseparables (Bakhtin, 1991; Bakhtin y Medvedev, 1991; Voloshinov, 1986).

¿Qué dicen realmente los textos escolares? ¿Qué elementos sociales contribuyen a conformar los textos? ¿Qué mecanismos generadores de significado pueden ser vistos en ellos? ¿Qué procesos de construcción de la semiosfera se desprenden del análisis de los contenidos que promueven los textos escolares? Son las preguntas que han guiado a nuestras indagaciones e intentamos sintetizar aquí algunas de las respuestas. 


\section{EL MARCO CONCEPTUAL DE NUESTRA INDAGACIÓN}

Una precisión sobre nuestro objeto de estudio se hace necesaria: no nos referimos a los textos específicos de algún contexto en particular, ni apuntamos en nuestra discusión a contribuir técnicamente a mejorar los textos concretos de algún área, sector o subsector del conocimiento escolar, como lenguaje y comunicación o ciencias sociales. Nuestra discusión no es sobre el texto concreto, es sobre el objeto texto escolar en cuanto modelo.

Entre aquel objeto y la realidad de la escuela debe existir alguna relación de lo contrario caeríamos en un clásico idealismo filosófico y no es nuestra intención. Entendemos que entre modelo y realidad existe una relación dinámica, dialéctica, pues no hay una oposición absoluta entre lo concreto real (en este caso el texto escolar) y el objeto pensado (el modelo); ${ }^{1}$ entre ellos existe una unidad dada como relación de conocimiento (Sánchez Vázquez, 1986). El modelo apunta a estructurar y hacer comprensible la realidad caótica del mundo de la vida cotidiana, pero la realidad social ilumina a su vez a los modelos.

Uno de los supuestos que nos guían se fundamenta en lo que tanto Lotman (1968, p. 123) como Voloshinov (1986, p. 13) han desarrollado en sus indagaciones: la palabra es por excelencia expresión de ideología. No existen textos totalmente libres de ideología, entendida esta como la visión de mundo o lectura de la realidad que se relaciona con un determinado poder. Los textos están cruzados y marcados por visiones de mundo estrechamente relacionadas con intereses concretos de poder vinculados a clases sociales y a grupos étnicos o a géneros. Este supuesto, basado en la relación entre ideología y poder, rechaza la concepción de que existiría una mirada técnica, totalmente neutra que impregna la construcción de los textos escolares.

Poder y texto están relacionados; en situaciones de abierto totalitarismo, los textos tienden a ser monológicos, no hay en ellos espacio para la diversidad, para la presencia de distintas voces. Cuando las fuerzas sociales tienen acceso al poder en términos participativos, cuando hay espacios y momentos de democracia en la sociedad, las voces que se escuchan en los textos pueden también ser variadas; el texto pasa a convertirse en polifónico. No basta sin embargo que un texto permita la polifonía, la expresión de voces variadas. ¿Qué sucede si todas aquellas voces en el fondo dicen lo mismo? De acuerdo con la perspectiva de Voloshinov (1986, p. 23), uno de los miembros del círculo de Bakhtin, podríamos decir que entonces estamos ante un texto monoacentuado. Un texto que verdaderamente propicie el diálogo, desde esta perspectiva debería ser, además de polifónico, multiacentuado es decir permitir la presencia de distintos acentos o evaluaciones sociales de la realidad social. Estamos ante dos oposiciones binarias de interés para comprender la composición de la semiosfera: la oposición entre monólogo vs diálogo y la oposición monoacentuación vs multiacentuación. ${ }^{2}$

1 Sobre esta relación entre objeto pensado, como abstracción que facilita el estudio de un fenómeno, y el objeto real, particular, Larsen (1990, p. 26) comenta que esa abstracción posee una existencia también real.

2 No vemos estas oposiciones binarias como estáticas, sino que, siguiendo la tradición semiótica dialéctica de Lotman (1990), consideramos que existe una relación entre aquellos fenómenos opuestos; éstos cobran sentido solamente en relación con sus alternativas, presentes o silenciadas. 
Uno de nuestros supuestos - siguiendo las nociones semióticas de Wells (1999, p. 136) con sus raíces en el neo-vygotskianismo - es que el texto escolar funciona como un artefacto cultural, es decir que encarna materialmente la cultura, actuando como una herramienta mediadora del saber y sobre ese fundamento desarrollaremos la exposición. La transmisión y reproducción del saber ha sido, a lo largo de la historia del desarrollo humano, mediada por artefactos materiales. El texto escolar ha sido uno de esos artefactos. Dicha herramienta mediadora del saber llegó a cobrar una especial relevancia durante el período moderno de construcción de los estados nacionales y su importancia aún perdura.

Dirigiremos el foco de nuestra discusión a las características de los textos, pero al mismo tiempo ilustraremos nuestra discusión con ejemplos concretos de investigaciones empíricas desarrolladas en diversos contextos culturales. El área abarcada por las investigaciones seleccionadas está constituida por textos pedagógicos de historia y de lenguaje puesto que estos están directamente involucrados en la construcción de la semiosfera. Utilizaremos para organizar la presentación de nuestras reflexiones la clásica forma de las tesis.

\section{TESIS SOBRE EL TEXTO COMO ARTEFACTO CULTURAL}

Tesis 1. El texto escolar como artefacto cultural está socialmente condicionado. No puede ni debe ser reducido a las condiciones sociales pues tiene una autonomía relativa, pero no puede ser comprendido como un producto cultural totalmente independiente, al margen de la sociedad.

¿En qué sociedad surgen y se desarrollan determinados textos escolares? ¿Cómo se sitúa el productor (o los productores) de textos en esa sociedad? ¿Cuál es su relación con el poder? ¿Qué presiones ejercen y qué soluciones exigen las necesidades sociales y el poder dominante? ¿Qué paradigmas se imponen (y cuáles se silencian) en el campo pedagógico y, por consiguiente, en el textual en ciertas condiciones históricas?

Estas preguntas distan de ser retóricas y constituyen el punto de partida para el campo de posibilidades de análisis que implica la primera tesis. No entendemos ni interpretamos el condicionamiento social del texto escolar como un fenómeno social total, para usar los términos de Durkheim (2005), sobre los actores y agentes sociales. Pero no se puede ignorar, con un simple acto de voluntarismo, que la producción de textos tendrá lugar en un medio social determinado que influirá directamente en las condiciones de producción de los textos pedagógicos. Hemos indicado que, entre el objeto de estudio, el modelo, y el objeto concreto existe una relación, para usar las palabras de Sánchez Vázquez (1986, p. 98) “[...] lo real debe intervenir en el proceso de conocimiento". Ilustraremos la primera tesis con un ejemplo del contexto del Báltico.

La incorporación de Estonia a la Comunidad Europea, y la elección por parte de la élite gobernante del modelo neoliberal (y su rechazo a un capitalismo que fomente el Estado de bienestar) ha teñido poderosamente el lenguaje escolar y sus textos, propiciando el individualismo y la competencia en desmedro de ideas y metas relacionadas con la solidaridad y el colectivismo (Aava, 2010). 
El análisis crítico de discurso de Aava (2010) aplicado al material textual escolar y educativo hoy en uso en aquella zona del Báltico, nos confirma que el texto pedagógico es condicionado socialmente. No sería posible comprender estos desplazamientos en los acentos y temas de los discursos escolares en aquella área sin incluir en el análisis las grandes transformaciones sociales que comprendieron la desaparición de la Unión Soviética, el consiguiente proceso de independencia de las naciones de la región y la verdadera ocupación neoliberal posterior, enmarcada en la incorporación de los países del Báltico a la Comunidad Europea.

Otro aspecto central en el condicionamiento social de los textos lo constituye el rol de los productores y editores de textos. Los productores de textos pedagógicos, en cuanto individuos, disponen de la libertad personal de elegir, pero esas decisiones se hacen no en un vacío existencial y con total autonomía, sino que dentro de condicionamientos objetivos. Un ejemplo de ello lo constituye la producción de textos escolares en la región escandinava. La producción textual en el campo pedagógico de Noruega es un proceso comunicativo dialógico, abierto y democrático. Participan en él no solo especialistas, también profesores y estudiantes y los plazos temporales de producción llegan a extenderse a dos años (Ajagan Lester, 2012). En Latinoamérica - y particularmente en Chile - la producción de textos pedagógicos es más restringida en cuanto a la participación de la comunidad escolar y académica y los plazos que enmarcan el trabajo son notablemente más limitados que los del contexto nórdico. Las elecciones de los productores de textos estarán, por consiguiente, influidas y determinadas por condiciones sociales objetivas. Incluir estas condiciones sociales en el análisis de la construcción del artefacto cultural, que es el texto escolar, contribuye a la comprensión de la relación texto-sociedad.

Tesis 2. El texto escolar puede ser analizado como estructura dentro de un sistema y puede ser estudiado como proceso histórico. Las dos visiones no son excluyentes, hay una relación dialéctica, continua e indivisible entre ambas.

El texto pedagógico o escolar puede ser visto como estructura y, en tanto estructura, será estudiado y analizado primordialmente desde la perspectiva sincrónica. ¿Qué significan hoy los mensajes propuestos por los textos? ¿Qué rol juegan o desempeñan los textos pedagógicos en el sistema escolar? Son preguntas válidas a nuestro entender, y de hecho se formulan hoy, por ejemplo, en el análisis lingüístico de los mensajes que construyen percepciones y visiones del rol de la mujer en la sociedad. Sin embargo, al poner dichos análisis el acento en la mirada y lectura eminentemente lingüística sincrónica de los textos, se pierden o desaparecen ciertas dimensiones históricas de los procesos analizados. ${ }^{3}$

$\mathrm{El}$ análisis de los textos como procesos históricos, la mirada diacrónica y longitudinal, permite la comprensión de las transformaciones en las interpretaciones presentadas y propuestas por los textos escolares. Un ejemplo relevante lo podemos

3 Es el caso del análisis del discurso sobre la mujer en manuales escolares chilenos, de Fernández Darraz (2010) que al enfatizar el análisis lingüístico descriptivo y sincrónico pierde de vista las valoraciones sobre la mujer que se hacían en la época pretérita estudiada, cayendo así en una mirada anacrónica. 
encontrar en los relatos contenidos en los textos escolares de historia utilizados en Suecia para narrar y explicar las características de la guerra civil finesa ${ }^{4}$ (Augustsson y Lundgren, 2014). El análisis de un período que se extiende desde 1960 a 2009 de diecisiete textos escolares demuestra que los relatos han variado desde el énfasis en las contradicciones puramente ideológicas hasta enfatizar como explicación las contradicciones de clases (énfasis que marcará los textos durante los años 1970 y 1980).

Postulamos que estas miradas - la sincrónica y la diacrónica — no debiesen ser consideradas ni como excluyentes ni como antagónicas; siguiendo la propuesta dialéctica desarrollada por los miembros del círculo de Bakhtin (1991) y por Lotman $(1999,1990)$ consideramos que los textos escolares pueden ser estudiados y analizados tanto desde el punto de vista de la sincronía, destacando la existencia de estructuras, pero sin perder de vista la existencia de incesantes transformaciones diacrónicas, es decir, la perspectiva histórica. El interrogarnos sobre cómo se explican aquellas relaciones nos conduce a la tercera tesis.

Tesis 3. El tipo de explicaciones que un texto de historia o ciencias sociales proponga (o la ausencia de ellas) puede condicionar la creación de representaciones mentales colectivas.

El relato histórico y los relatos sobre la sociedad implican, como todo relato, la selección de ciertos significados, la omisión de otros y la formulación de ciertas explicaciones sobre aquellos significados, hechos y procesos. El cómo se explique un suceso histórico no es en modo alguno un rasgo irrelevante de los textos escolares. $¿$ ¿Se reduce la explicación a tomar en cuenta solamente las intenciones de los actores sociales? aquello que Von Wright (1971, p. 83-84) ha denominado explicación teleológica ¿ $\mathrm{O}$ se la reduce a los fenómenos económicos, a la base? ¿ $\mathrm{O}$ a una suma de "factores"? ¿Se acentúa la continuidad o son enfatizadas las rupturas? ¿Se reparten "las culpas históricas" equitativamente - como parecen hacerlo los textos escolares de historia suecos cuando explican la guerra civil finesa (Augustsson y Lundgren, 2014) - inculpando de la misma barbarie a los dos bandos?5 ¿O se atribuye a la historia una capacidad predictiva, suponiendo que aquello que sucedió de determinada forma en el pasado se repetirá en el futuro de la misma manera?

Interesante en el contexto chileno es observar que los textos de ciencias sociales presentan una versión de la responsabilidad por las violaciones a los Derechos Humanos durante el Golpe de 1973 - y, posteriormente, durante la dictadura militar - que consiste en explicarlas como una responsabilidad transversal: todos los chilenos serían igualmente responsables de aquellas violaciones. Este efecto se logra por medio de diversos recursos lingüísticos, uno de ellos la omisión de agentes

4 De enero a mayo de 1918, Finlandia se vio profundamente dividida y convulsionada por una guerra civil que enfrentó a las fuerzas de la burguesía ("los blancos") con las del proletariado finés ("los rojos").

5 Hoy se conoce, por el acceso a nuevas fuentes que alrededor de diez mil prisioneros del bando de los denominados "rojos" fueron exterminados en campos de concentración como producto del hambre, las enfermedades, los malos tratos y las ejecuciones sumarias (Augustsson y Lundgren, 2014). 
de las graves violaciones a los derechos humanos ocurridas durante ese período (Molina Conejeros, 2014).

Otros enunciados sobre estos momentos históricos analizados por el mismo autor muestran la tendencia a explicar el golpe cívico militar a partir de una suerte de fatalismo histórico: desde la versión acuñada y propuesta en los manuales estudiados, el golpe cívico militar de 1973 habría sido inevitable. El quiebre de la institucionalidad hasta entonces vigente y la extrema radicalización de las fuerzas políticas en pugna habría desembocado en la inevitable intervención militar. Este tipo de explicaciones son construcciones que poseen un claro sesgo ideológico, distan de tener fundamentos objetivos y científicos y tienden a defender la ruptura de la institucionalidad.

La importancia del tipo de explicaciones que se propongan en los textos radica en que pueden contribuir a condicionar la creación de representaciones mentales colectivas, compartidas por los miembros de una comunidad. Las características de las explicaciones que en ellos se ofrezcan coadyuvarán a construir creencias (Van Dijk, 1999). El carácter de texto oficial que posee el texto escolar puede conducir a una recepción que convierta aquellas explicaciones en verdades también oficiales.

Voloshinov (1986, p. 91) trazaba una distinción entre ideologías como sistemas de ideas establecidos y las que circulan en un nivel no fijo, asistemático, y que constituyen una suerte de atmósfera compuesta por discursos, interiores y exteriores, que dotan a nuestras acciones y conductas de sentido, la ideología comportamental. Las explicaciones de los textos asimiladas acríticamente pueden llegar a ser componentes de estas dos esferas de la ideología. Y esta última afirmación nos remite a una nueva tesis.

Tesis 4. El texto escolar impone significados pues su creación responde a relaciones de poder; sin embargo, el texto es decodificado y esa decodificación puede reelaborar, recrear, abolir y superar los mensajes oficiales, proponiendo mensajes y lecturas alternativas. Una decodificación crítica puede incorporar la tradición de los oprimidos a la interpretación de los procesos sociales e históricos.

Resulta acertado señalar que el texto escolar impone significados, puesto que los procesos de producción de los mismos están condicionados por relaciones de poder; son quienes se han apoderado del centro del campo pedagógico (campo en el sentido propuesto por Bourdieu, 1994, p. 73-75) quienes influyen en la construcción/creación de los textos (sin por esto menospreciar la influencia de la tradición de codificación de cada sistema escolar). Sin embargo, esos significados no se dan al margen de hombres y mujeres concretos/as, que se relacionan y que actúan socialmente (Sánchez Vázquez, 1997).

Acentuar excesivamente el rol del texto como un artefacto cultural que impone significados conduce a un análisis unilateral que sobredimensiona las posibilidades de dominación de dicho artefacto. Esta interpretación, que acentúa la dominación de los enunciados de los textos escolares, deja de lado el hecho de que la lectura implica un proceso de semiosis. Esto significa que las palabras que conforman el enunciado, o los enunciados, son interpretados por medio de la creación de una serie, en prin- 
cipio infinita, de nuevos signos con los cuales se interpretan, se explican y traducen los antiguos signos (Eco, 1991, p. 69; Greimas, 1990, p. 140; Jameson, 1988, p. 191).

El proceso de semiosis de los enunciados contenidos en el texto escolar se da cuando este es recontextualizado en el aula, es decir cuando es sacado del contexto de la producción oficial y es ubicado en un nuevo contexto, el de la lectura que recreará los significados, aquello que algunos curriculistas denominan el curriculum realizado (Gimeno Sacristán, 1988, p. 124). De manera tal que los agentes sociales que recontextualicen un texto que afirme que el cruce del Biobío por parte del Ejército de Chile, y por consiguiente del Estado nacional, fue una campaña de Pacificación de la Araucanía pueden proponer a sus estudiantes una lectura alternativa: que se trató de una ocupación y de un genocidio. Al hacerlo estarán iniciando un proceso de semiosis que puede dar paso a interpretaciones alternativas a los mensajes contenidos en los enunciados de los textos oficiales. Sin embargo, a su vez, los estudiantes pueden rechazar la lectura crítica propuesta por el/la docente e inclinarse por la versión que propone el texto como producto del respeto y fe en los textos oficiales considerados como Autoridad (Englund et al., 2003, p. 161-178).

El proceso de recontextualización de los manuales significa desarrollar la semiosis en un nuevo contexto: el del aula y sus actores, estudiantes y docentes. El contexto, tanto los referentes físicos como las condiciones sociales de la semiosis, serán decisivos para la comunicación; la semiosis no es nunca totalmente simple, clara, ni absolutamente racional.

$\mathrm{Si}$ se ignoran aquellos procesos y condiciones se corre el riesgo de convertir al texto pedagógico, en el plano del análisis, en un fenómeno total que simplemente se impondrá a los sujetos. Los docentes, más allá de las limitaciones que impone el texto escolar, los usan, decodifican y pueden resemantizar los discursos hegemónicos presentes en esos manuales, como lo demuestra el análisis de las actividades de resistencia al contenido de los textos oficiales desarrolladas por docentes argentinos durante la dictadura militar (Postay, 2006). Las acciones de los profesores (uso del curriculum nulo, diseño de teatralizaciones, construcción de manuales alternativos, la inserción de disputas por el juego del lenguaje) propusieron significados distintos a los oficiales, evidenciando así que, si bien el texto limita el quehacer docente, no se debe ceder ante la tentación teórica de un determinismo textual.

Tesis 5 . Un texto puede tender a la multiacentuación y polifonía o bien a la monoacentuación y monofonía; un texto multiacentuado y polifónico no impondrá una visión única de la realidad y dará espacio a voces y acentos diversos. Un texto monoacentuado y monofónico tenderá a eliminar o silenciar visiones de mundo alternativas, acallando determinadas voces. Su calidad de monofónico y monoacentuado o polifónico y multiacentuado lo determinarán las condiciones sociales.

Un texto puede dar lugar a la presencia de diversos acentos, es decir de perspectivas y de evaluaciones sociales; esto acostumbra a suceder cuando fuerzas sociales centrífugas provocan profundos cambios en el conjunto de la sociedad. La multiacentuación propone textos abiertos a la discusión y a la reflexión. Un texto polifónico implicará la presencia de diversas voces en él, las que se pueden generar a través de fuentes distintas, tales como crónicas y relatos. 
La monoacentuación se puede apreciar cuando fuerzas centrípetas, estabilizadoras, tienden a originar textos autoritarios. Es relevante considerar que un texto monoacentuado - aquel que privilegia una sola perspectiva, la de los sectores social y políticamente dominantes - puede ser también polifónico, dar espacio a diversas voces, pero todas aquellas voces pueden apuntar a lo mismo. Un claro ejemplo de aquello son los textos escolares creados en Europa durante la época del colonialismo clásico. Éstos daban espacio a las más variadas voces (administradores coloniales, militares, colonos y viajeros) recontextualizando crónicas de viajes y relatos que eran insertados, por su alto valor de entretención y por su exotismo, en los textos escolares. Aquella polifonía estaba al servicio de un solo acento ideológico: justificar la "misión civilizadora" de Occidente en África y en otros lugares, legitimando así el despojo de países militar y técnicamente menos desarrollados que los de las metrópolis europeas.

Ejemplos notables de procesos en esta dirección de monoacentuación en Latinoamérica, los encontramos en la época de las dictaduras militares iniciadas con los golpes de los años 1970, basadas en la doctrina de seguridad nacional, cuando los textos fueron depurados de voces y acentos que eran evaluados como enemigos de la nación y como un peligro para la unidad y seguridad de la patria; en el caso de Argentina, la Junta militar gobernante lanzó una campaña de depuración de textos y sólo los aprobados y recomendados por la censura podían ser usados en las aulas en lo que ha sido denominado como monólogo autoritario (Pineau, 2006).

La masiva circulación de los textos escolares y su carácter de portadores de un saber legítimo los convirtió en un medio privilegiado para reconstruir la identidad nacional argentina sobre la base de principios cristianos tradicionales y conservadores. Otro componente central de los textos escolares de aquella época lo constituía el militarismo que se expresaba en el mensaje reiterado a los jóvenes exhortándolos a cumplir con el servicio militar, y la constante apelación a defender los límites patrios y las fronteras. La visión militarista de la vida, un nacionalismo exacerbado, la presencia de un Dios todopoderoso y conservador fueron los acentos que caracterizaron a los textos escolares argentinos de la época. Se trataba no solo de eliminar y reprimir mensajes adversos, sino también de consolidar una doctrina que sustituyese las ideas que se pretendía eliminar (Artieda, 2009; Carbone, 2006).

Los profundos cambios sociales que causaron el arribo de un sistema democrático en Argentina provocaron una modificación radical en los textos de ese país. El estudio de los textos post-dictadura (Coria, 2006) nos indica que nuevas estrategias pedagógicas fueron acuñadas para seleccionar, organizar y presentar los saberes escolares. De dominar solamente acontecimientos la mirada se desplazó al estudio de los procesos; de la simple descripción de hechos a explicaciones históricas; del reduccionismo del suministro de datos a las conceptualizaciones; de textos que remitían al pasado a textos que interrogaban sobre el presente, multiacentuando profundamente a los textos escolares. Estos cambios en el plano textual no pueden 
ser desvinculados de los sociales, los cuales crearon las condiciones para la democratización de los textos. ${ }^{6}$

Tesis 6. Un texto escolar es, en sentido amplio, dialógico puesto que dialoga con voces actuales y con voces del pasado. Debe ser entendido en relación con un movimiento dialéctico: como reproducción de lo ya dicho en el pasado, pero también como creación de nuevos enunciados, mensajes, códigos e ideologías.

Hemos postulado en las tesis anteriores la necesidad de poner los textos y los determinantes del autor, en relación con todo el entramado social que lo sustenta para poder entender las complejas relaciones entre textos escolares y las producciones ideológicas. Una mirada al texto como un activo componente de la producción ideológica nos lleva a analizar su relación con la construcción y reproducción del relato histórico.

Desde esta perspectiva el texto puede ser visto como constructor de la historia, pero también como reproductor de la misma. Esta visión de los enunciados sobre historia propuestos por un texto escolar rechaza una visión lineal de los fenómenos sociales y - siguiendo los lineamientos bakhtinianos y de Lotman - apunta a una lectura que capture el dinamismo de aquellos procesos, su productividad.

El estudio longitudinal de textos de historia chilenos (Minte Münzenmayer, 2005) revela la creación de un verdadero canon que a través de décadas ha contribuido a reproducir acríticamente voces autoritarias del pasado, por ejemplo, ensalzando la figura de Diego Portales y contribuyendo a cimentar una mentalidad autoritaria. Fenómenos similares encontramos en contextos tan distantes del chileno como el griego y el turco.

Mal se puede entender la identidad nacional griega actual si no se toma en cuenta la narrativa propuesta por los textos escolares durante largas décadas, afirma Heraclides (2011). Esta narrativa ha reproducido una imagen absolutamente idealizada de la nación griega, la que se habría constituido hace miles de años atrás; un proceso similar de reproducción de concepciones profundamente chauvinistas a lo largo de extensos períodos históricos se puede apreciar en textos del sistema escolar turco (Madra, 2008). Concepciones nacionalistas, que deben ser ubicadas y comprendidas en el contexto de la creación del Estado nacional moderno turco, que han impregnado los manuales y textos escolares en aquel país.

Sin embargo, como indicábamos, estos procesos distan de ser lineales; en el caso de Turquía, los cambios sociales introducidos por la globalización han significado el cuestionamiento de temas percibidos como tabús por buena parte de la intelectualidad y, entre ellos, los productores de textos, tales como la identidad nacional y los discursos estatales (Algan y Haydari, 2013). Los efectos de la globalización han significado, además, el inicio del debate sobre los mensajes relacionados con estas materias. Si bien los textos escolares y pedagógicos

6 Hay aún pendientes, agrega Amézola (2006, p. 223-272), dificultades y desafíos, puesto que al quedar testigos y sobrevivientes del período que se intenta estudiar, se enfrentan conceptos diferentes de la historia: el existencial por un lado y el erudito por otro, la memoria de los sujetos y los archivos. 
se vuelven hacia el pasado posicionándose en un eje vertical, tal como señalaba Kristeva (1975), y ellos pueden reproducir activamente ideologías y mentalidades, consideramos que se debe evitar el reduccionismo de la visión unilateral centrada exclusivamente en la reproducción.

La acumulación de enunciados críticos crea nuevos mensajes, nuevos textos; voces críticas actuales (las del eje horizontal), coadyuvan a la deconstrucción activa de los textos como sucede con la revisión de los textos relacionados con el golpe cívico militar chileno, el argentino, y otros sucesos históricos y sociales altamente complejos en su interpretación. De aquella lectura crítica deben surgir nuevos textos, por el hecho de que la reproducción no es necesariamente ni circular ni un proceso fatal, dado de una vez para siempre.

Los códigos gobiernan la emisión de mensajes, sin embargo, nuevos códigos y nuevas ideologías pueden surgir al ser éstos reestructurados por nuevos mensajes. Esta relación dinámica, este movimiento continuo entre códigos y mensajes constituye la base para la comprensión de una producción textual regida por reglas y una creatividad que cambia las reglas (Eco, 2011; Voloshinov, 1986).

Tesis 7. El texto escolar en cuanto artefacto cultural traza límites existenciales y contribuye a la separación de "nosotros" (el endogrupo) de "ellos" (el exogrupo). En las representaciones mentales colectivas creadas por esos límites nuestro espacio es armonioso, seguro y culto, nos pertenece; el espacio de ellos es "otro", hostil, peligroso y caótico. El texto escolar ha sido utilizado históricamente para trazar aquellos límites y sigue siendo un mecanismo generador de diferenciaciones.

La creación/organización de la semiosfera se funda en diversos ejes y subestructuras; uno de esos ejes lo constituye el espacial que funciona como una coordenada que organiza el espacio en interno y externo y delimita la frontera entre ellos. La coordenada espacial se relaciona directamente con la construcción de la cultura puesto que cada cultura comienza con la separación del mundo dividiéndolo en "nuestro" espacio interno y el de "ellos", el externo, asevera Lotman (1990, p. 131).

Aquel trazado de límites ha separado durante el curso de la historia de la humanidad a "pueblos nómades" de "pueblos urbanos"; a "bárbaros" de "civilizados"; a "supersticiosos" de "practicantes de la fe verdadera"; a "violentos, crueles y sanguinarios" de "pacíficos, cultos y refinados"; de quienes "no poseen lengua" de los que "tienen una lengua verdadera"; a "pueblos inferiores" de "pueblos superiores"; a "pueblos sin historia" de "pueblos que crean la historia"; a "pueblos de la naturaleza" de "pueblos cultivados"; a quienes están más "cerca de lo animal" de los "verdaderamente humanos"; a "irracionales" de "racionales" (Ajagan Lester, 2000; Lotman, 1990; Reissner, 1983). En este trazado de límites, en esta creación de espacios semióticos, los textos escolares han tenido una importante participación, adoctrinando a millones de ciudadanos en visiones ideológicas de la realidad coadyuvando a la creación de un "nosotros" que se percibió (y percibe) como superior y un "ellos" considerados como inferiores (Ajagan Lester, 2012).

Los límites entre "ellos" y "nosotros" han ido variando y se han ido modificando a lo largo de la historia. Durante siglos la distinción entre "descubridores" y "descubiertos" fue parte del sentido común dominante en Occidente y en su periferia. 
Los textos escolares, y también los diccionarios y enciclopedias (Reissner, 1983), contribuyeron activamente a su reproducción y naturalización. Aquel límite se constituyó en un componente acríticamente aceptado de la ideología tanto en su expresión de ideas sistemáticas como en su versión - más difusa pero no menos efectiva - de las ideologías comportamentales. Actualmente, la acumulación de mensajes críticos en contra de aquella lectura de la historia, con claras connotaciones eurocéntricas y colonialistas, ha permitido su desplazamiento de la interpretación de los procesos históricos de conquista, ocupación, genocidio y colonización y su reemplazo por nuevas unidades culturales.

Otra distinción célebre entre "ellos" y "nosotros" fue la establecida por la biología racial (o doctrina craneológica), la que trazó - durante buena parte del siglo XIX y la primera mitad del siglo XX — un límite apelando a la diferenciación entre pueblos dolicocéfalos (de cráneo alargado) y pueblos braquicéfalos (de cráneo corto). De acuerdo con este paradigma, aceptado por la comunidad científica internacional como ciencia normal hasta prácticamente 1950, los pueblos dolicocéfalos constituían una raza superior, y estaban en condiciones de producir civilización y cultura. Por el contrario, los pueblos braquicéfalos eran - desde la perspectiva de este paradigma biologicista - inferiores y no estaban en condiciones de producir cultura, al menos no refinada ni "superior". Tampoco podían pensar racionalmente. Interesante en el marco de nuestra indagación es constatar que los textos escolares europeos, especialmente los del contexto cultural del norte de Europa, reprodujeron estas concepciones racistas como parte del conocimiento oficial prácticamente durante más de medio siglo.

Aquellas diferenciaciones constituyen en la actualidad lo que Lotman (1968, p. 281) denominó "no textos", es decir textos imposibles de ser producidos puesto que el entramado actual de la cultura ya no los permite ni los tolera. Sin embargo, nuevos límites son hoy trazados para distinguir el espacio semiótico de la periferia del espacio semiótico del centro. Así, textos escolares europeos que han dejado tras de sí la actualmente inaceptable y rechazada distinción entre descubiertos y descubridores, proponen nuevos límites existenciales en torno a materias tales como los Derechos Humanos: "Nosotros tenemos derechos humanos y somos capaces de respetarlos", "ellos carecen de derechos humanos y no son capaces de respetarlos" es el mensaje subyacente tanto en las imágenes como en los textos escritos, el cual contribuye a continuar reproduciendo la visión de la superioridad europea sobre los no europeos, los inferiores (Ajagan Lester, 1999, p. 131).

Otro límite que reemplaza a los antiguos en la generación de significados en los textos escolares del centro se funda sobre la base de criterios económicos: "Nosotros tenemos un alto estándar de vida", "Ellos carecen de un alto estándar de vida" (Ajagan Lester, 2000, p. 201). Resulta interesante en este contexto recordar la observación de Memmi (1973, p. 113) cuando señalaba que los colonizadores acostumbraban a definir a los colonizados no a partir de lo que eran, sino desde la perspectiva de que se trataba de seres que carecian de ciertas características o bien psicológicas o bien éticas. Aquel punto de referencia en la cartografía mental de los productores de textos europeos - "el otro" como "un ser que carece de" — parece seguir orientando su construcción de la cultura. 
¿En qué sociedad surgen y se desarrollan determinados textos escolares? preguntábamos al formular la primera tesis. Es importante desde la perspectiva del trazado de límites existenciales tener presente que tanto la escuela nacional como los textos escolares nacen directamente ligados a la creación del Estado nacional (Hobsbawm, 1998). La escuela y los textos serán fundamentales para crear una identidad nacional. Serán decisivos para formar ciudadanos que renuncien o atenúen su pertenencia a identidades locales, regionales, y adoctrinarlos de manera tal que estén dispuestos incluso a dar la vida por aquella comunidad política imaginada, como reza la lograda expresión de Anderson (2006, p. 23), que es la nación.

La construcción de la nación ha supuesto imponer un proyecto que borrase las diferencias existentes en la población para de esta forma crear una nación uniforme (Teobaldo y Nicoletti, 2009, p. 68); esto explica el tratamiento que los textos escolares en buena parte de Sudamérica han dado a los pueblos originarios, mostrándolos como seres incivilizados, incapaces de utilizar productivamente las tierras conquistadas y "vacías", homogeneizándolos pero, al mismo tiempo, convirtiéndolos en ciudadanos de segunda categoría, subordinados al poder político, militar y económico de los "blancos".

El estado nacional es creado/construido en competencia y lucha contra otros estados nacionales, pugna que se refleja y refracta en los textos escolares, los que en su narrativa convierten a estados de países vecinos, históricamente rivales, en "el Otro" por antonomasia. Componente fundamental en esta construcción ha sido la idealización del pasado, lo que podemos apreciar, $v$. $g r$. en los textos escolares griegos y turcos. La narrativa de los textos griegos propone a los estudiantes una historia marcada por una continuidad de tres mil años, sin rupturas, desde tiempos homéricos hasta el presente. Desde esta perspectiva los griegos actuales serían descendientes directos de los "antiguos griegos". En ese imaginario el enemigo tradicional, "el Otro", son los turcos, quienes serían “incivilizados” "bárbaros” hasta la actualidad. Existe, además, un "Otro" más atenuado en aquella narrativa, constituido por el Occidente católico-romano (Heraclides, 2011, p. 12-14).

Por su parte los textos escolares turcos retratan a un pueblo con sus raíces en un pasado muy lejano, creador de la mayor civilización antigua en el Asia Menor, Mesopotamia y otras regiones del área. Y ese pueblo sería la quintaesencia de los constructores de estados a través de los siglos (Heraclides, 2011, p. 13). Hay dos períodos importantes en los textos de historia turcos: la del período del Imperio Otomano, y allí "los Otros" irán variando de acuerdo con los avatares de las conquistas y luchas territoriales: China, Irán, Austria-Hungría, Rusia, Francia. En el segundo período, el de la República moderna, el “Otro" será Grecia. En los relatos turcos actuales los griegos no se relacionan con los antiguos helenos, sino que son descendientes de un abigarrado grupo de cristianos que vivían en el Imperio Bizantino, decadente y cruel (Heraclides, 2011).

Procesos similares pueden ser apreciados en el contexto escolar sudamericano. Una revisión de treinta y cuatro textos escolares brasileros de historia, de distintos niveles de enseñanza, que abarcan desde el siglo XIX hasta el XXI, muestra que los relatos en ellos contenidos han contribuido a la construcción de la nación, creando una identidad unitaria $y$, al mismo tiempo, como parte de este proceso 
han construido enemigos: Argentina y, en menor grado, Uruguay: "A invenção da Argentina como inimigo é também a invenção do Brasil como unidade identitária, uma nação" (Munakata, 2009, p. 30).

En los procesos de construcción de la identidad ha intervenido desde antiguo esta delimitación negativa del "Otro", con el fin de crear una visión positiva de "Nosotros". Existe en la actualidad un proceso paradojal que se relaciona con la globalización: los acercamientos entre naciones y actores sociales que provocan las nuevas tecnologías, los contactos estimulados por las migraciones masivas, la creación de sociedades postindustriales, tienden - por un lado - a erosionar al Estado nacional y, por consiguiente, a debilitar la identidad ligada a él (Bauman, 2013; Beck, 2001; Habermas, 2006). Ese desgaste de las viejas concepciones del estado nacional se refleja y refracta también en los textos escolares; pero, por otro lado, se refuerzan viejas identidades nacionales que recurren a discursos nacionalistas de viejo cuño, como en el caso de la Rusia actual. Esos discursos tienen eco en el plano del relato de los textos escolares y continúan creando/recreando nuevas y viejas otredades (Karpov y Lisovskaya, 2005, p. 28).

\section{REFLEXIONES FINALES}

La compleja relación entre sociedad, cultura y texto escolar no es unidireccional; como se desprende de los estudios empíricos reseñados se trata de fenómenos complejos y contradictorios. En ellos intervienen actores sociales que dominan el centro del campo pedagógico, pero también otros, situados quizás en los márgenes del mismo desde el punto de vista del poder, como profesores y estudiantes, pero que intervienen activamente en la recepción, interpretación y creación de mensajes. El poder no es monolítico ni estático, puede ser entendido como relación y en la creación del poder pueden participar, y participan, también sujetos sociales concretos.

El texto escolar condiciona, pero a su vez es condicionado; puede ser analizado desde la sincronía, pero también desde la diacronía; impone significados, pero esos significados pueden ser reconstruidos, recreados, abolidos y superados y pueden surgir nuevos mensajes, nuevos códigos alternativos a los oficiales. El texto es un lugar de encuentro de diversas voces, qué voces se impongan, cuáles sean escuchadas y cuáles silenciadas, será determinado por las condiciones sociales y políticas. El texto escolar reproduce, pero también produce nuevos mensajes, nuevos códigos alternativos. La mirada dialéctica de la escuela lotmaniana y del círculo de Bakhtin constituye un valioso auxiliar en este tipo de indagaciones. Lo fructífero de este análisis dialéctico nos indica que, pensado en sus orígenes para el estudio de textos poéticos, puede ser recontextualizado en el área pedagógica.

Los procesos de la semiosis no deben ser reducidos a lo social, pero tampoco deben ser separados ni de la sociedad, ni de la cultura ni del plano político; la creación del Estado nacional y los complejos cambios económicos, sociales, políticos y culturales que tienden a erosionarlo afectan al trazado de límites existenciales que se expresan en el texto escolar. Podemos observar que un mecanismo generador de sentido directamente relacionado con la construcción del Estado nacional han 
sido los relatos contenidos en los textos escolares, la construcción de un "nosotros" inclusivo y un "ellos/los Otros", excluyente.

Las tesis aquí postuladas y desarrolladas nos indican la necesidad de seguir las indicaciones que hacía Freire a lo largo de toda su obra, inspirándose en el Lukács de Historia y consciencia de clase (1969), en el sentido de evitar el estudio fragmentario de los fenómenos, incorporándolos en una totalidad que permita su comprensión.

Predomina en el material reseñado para ilustrar nuestras tesis la presencia de análisis textuales basados o bien en el análisis de contenido o bien en el análisis crítico de discurso; minoritarios son los estudios de recepción del mensaje de los textos escolares. Una tarea que parece seguir en buena medida pendiente es el análisis empírico de la recepción concreta en el aula de los textos escolares estudiados en el plano discursivo. ¿Cómo es interpretado este artefacto en el aula? ¿Cómo la autoridad que posee y transmite una verdad indesmentible? ¿Cómo un texto de apoyo que puede ser modificado y criticado? ¿Es ignorado y los docentes crean textos propios? Sabemos, por las experiencias argentinas comentadas, que el que un texto privilegie ciertos significados y excluya otros no es ni un proceso fatal ni irreversible. Las estrategias de recepción de los profesores bien pueden crear y proponer nuevos significados, nuevos mensajes y nuevos códigos superando/aboliendo los propuestos en los textos oficiales. La escuela no es solo un espacio de reproducción acrítica de saberes oficiales, puede también ser un espacio de resistencia, de lucha contra hegemónica. En aquellos procesos de resistencia los textos oficiales pueden ser resignificados.

El texto escolar impreso encuentra actualmente su hegemonía disputada por nuevos artefactos culturales en su mayoría digitales o electrónicos: videos, cd y otros medios didácticos propios del ciberespacio como páginas web, hipertextos, etc. que son los soportes actuales de la lectura. Sigue siendo, sin embargo, un artefacto material primordial en la transmisión de la cultura. Su estudio, su explicación/ comprensión en tanto artefacto fundamental de nuestra cultura, continúa siendo un desafío vigente.

\section{REFERENCIAS}

Aava, K. The analysis of estonian educational discourse. 2010. 300f. Tesis (Doctorado en Pedagogía) - Institute of Educational Sciences, Tallinn University, Tallinn, 2010.

Ajagan Lester, L. Text och etnicitet. En diskussion om etnisk självförståelse. In: SÄғsтröм, C. A.; Östman, L. Textanalys, introduktion till syftesrelaterad kritik. Lund: Studentlitteratur, 1999. p. 121-134.

. "De Andra”. Afrikaner i svenska pedagogiska texter (1768-1965). Stockholm: HLS Förlag, 2000.

Reflexiones en torno al texto escolar desde la perspectiva de la pedagogía crítica. Paideia - Revista de Educación, Concepción: Universidad de Concepción, n. 50, p. 49-70, enero/jun. 2012. 
Algan, E.; Haydari, N. When national taboos go global: collective memory, state and national identity in Turkey. In: Annual Meeting of the International Communication Association. San Francisco, CA: 15 dic. 2013. Disponible en: $<$ http://citation.allacademic.com/meta/p169935_index.html $>$. Acceso en: 2 jul. 2016. AmÉzola, G. Cambiar la historia. Manuales escolares, currículum y enseñanza de la historia reciente desde la transformación educativa. In: Kaufmann, C.(Dir.).Dictadura y educación. Los textos escolares en la historia argentina reciente. Buenos Aires: Universidad Nacional de Entre Rios; Miño y Dávila Editores, 2006. t. 3, p. 223-272.

Anderson, B. Comunidades imaginadas: reflexiones sobre el origen y la difusión del nacionalismo. México, DF: Fondo de Cultura Económica, 2006.

Artieda, T. L. (Comp.). Los "otros" en los textos escolares: conflictos en la construcción de imágenes de la nación. Luján: Universidad de Luján, 2009.

Augustsson, C.; Lundgren, F. Finska och spanska inbördeskriget $i$ historieläroböcker 1960-2009: En ideologianalys av 17 historieläroböckers framställning av finska och spanska inbördeskriget. Uppsala: Uppsala Universitet; Institutionen för pedagogik, didaktik och utbildningsstudier, 2014.

Bakhtin, M. La cultura popular en la edad media y en el renacimiento. Madrid: Alianza Editorial, 1987.

. Det dialogiska ordet. $2^{\text {nd }}$ ed. Gråbo: Bokförlaget Anthropos, 1991.

Bakhtin, M.; Medvedev, P. The formal method in literary scholarship: a critical introduction to sociological poetics. Baltimore and London: The Johns Hopkins University Press, 1991.

Bauman, Z. Globalización. Consecuencias humanas. México, DF: Fondo de Cultura Económica, 2013.

BЕск, U. Vad innebär globaliseringen? Göteborg: Daidalos, 2001.

Bourdieu, P. Raisons pratiques: sur la théorie de l'action. Paris: Éditions du Seuil, 1994. Carbone, G. M. Manuales de educación primaria: entre la clausura y la búsqueda de intersticios. In: Kaufmann, C. (Dir.). Dictadura y educación. Los textos escolares en la historia argentina reciente, 2006.t. 3, p. 41-104.

Coria, J. Concepciones acerca de lo social en los manuales de historia. De la dictadura al temprano siglo XXI. In: Kaufmann, C. (Dir.). Dictadura y educación. Los textos escolares en la historia argentina reciente. Buenos Aires: Universidad Nacional de Entre Rios; Miño y Dávila Editores, 2006. t. 3, p. 295-332.

Durkheim, E. Las reglas del método sociológico. México, DF: Fondo de Cultura Económica, 2005.

Eco, U. A theory of semiotics. Bloomington: Indiana University Press, 1991. . La estructura ausente. Barcelona: Random House; Mondadori, 2011.

Englund; B.; Hultén, B.; Mårdsjö Blume, K.; Selander, S. Texters auktoritet. In: Englund, B.; Ledin, P. (Reds.). Teoretiska perspektiv på sakprosa. Lund: Studentlitteratur, 2003. p. 161-180. 
Fernández Darraz, M. C. Las mujeres en el discurso pedagógico de la historia: exclusiones, silencios y olvidos. Universum, Talca: Universidad de Talca, v. 25, n.. 1, p. 84-99, 2010. DOI: http://dx.doi.org/10.4067/S0718-23762010000100007

Gimeno SACRISTÁn,J.El currículum: una reflexión sobre la práctica.Madrid: Morata, 1988. Greimas, J. A. The social sciences: a semiotic view. Minneapolis: University of Minnesota Press, 1990.

Habermas,J. Más allá del estado nacional. México, DF: Fondo de Cultura Económica, 2006. Heraclides, A. The essence of the greek-turkish rivalry: national narrative and identity. [S.1.]: Hellenic Observatory, 2011. Disponible en: <http://eprints.lse.ac.uk/45693/1/ GreeSE\%20No51.pdf>. Acceso en: jun. 2014.

Нов sваwм, E. Naciones y nacionalismo desde 1780. Barcelona: Crítica; Grijalbo, Mondadori, 1998.

JAMEson, F. The ideologies of theory. Essays 1971-1986. In: .The syntax of history. Minneapolis: University of Minnesota Press, 1988.v. 2.

Karpov, V.; Lisovskaya, E. Educational change in time of social revolution: the case of post-communist Russian in comparative perspective. In: EkLof, B.; Holmes, L. E.; Kaplan, V. Educational reform in post-soviet Russia: legacies and prospects. London: Frank Cass, 2005. p. 23-55.

Kristeva, J. Séméiotiké: recherches pour une sémanalyse (extraits). Paris: Éditions du Seuil, 1975.

Larsen, N. Modernism and hegemony: a materialist critique of aesthetic agencies. Minneapolis: University of Minnesota Press, 1990.

Lotman, Y. Teser till problemet "Konstens plats bland de modellbildande systemen". In: Aspelin, K.; Lundberg, B. A. Form och struktur: Litteraturvetenskapliga texter i urval. Stockholm: Bokförlaget PAN/Norstedt, 1968. p. 281-299.

. Universe of the mind: a semiotic theory of culture. London; New York: Tauris, 1990. . Cultura y explosión. Lo previsible y lo imprevisible en los procesos de cambio social. Barcelona: Gedisa Editorial, 1999.

LuckÁcs, G. Historia y consciencia de clase. Estudios de dialéctica marxista. México, DF: Grijalbo, 1969.

Madra, A. History, collective memory, and national identity: the case of Turkey. In: Annual Meeting of the American Sociological Association. Boston: 2008. Disponible en: <http://citation.allacademic.com/meta/p_mla_apa_research_ citation/2/4/2/4/9/pages242496/p242496-1.php>. Acceso en: 5 abr. 2017.

Меммi, A. Portrait du colonisé (précedé du portrait du colonisateur). Paris: Petite Bibliothèque Payot, 1973.

Minte Münzenmayer, A. Autoritarismo y pluralismo: visión crítica de la enseñanza de la historia de Chile. Concepción: Ediciones Escaparate, 2005.

Molina Conejeros, C. La nominalización como mecanismo de invisibilización: el golpe de 1973 y la dictadura militar en manuales escolares de historia y ciencias sociales. Paideia Revista de Educación, Concepción: Universidad de Concepción, n. 54, p.33-56, enero/jun. 2014. 
Munakata, K. A invenção da Argentina como inimigo. In: Artieda, T. L. (Comp.). Los "otros" en los textos escolares: conflictos en la construcción de imágenes de nación. Luján: Universidad de Luján, 2009. p. 13-34.

Pineau, P.Políticas pedagógicas de cuidado y espera: los libros de lectura para la escuela primaria en la dictadura. In: Kaufmann, C. (Dir.). Dictadura y educación. Los textos escolares en la historia argentina reciente. Buenos Aires: Universidad Nacional de Entre Rios; Miño y Dávila Editores, 2006. t. 3, p. 25-39.

Postay, V. Algunos usos de los textos de ciencias sociales en las escuelas cordobesas durante la dictadura. In: Kaufmann, C. (Dir.). Dictadura y educación. Los textos escolares en la historia argentina reciente. Buenos Aires: Universidad Nacional de Entre Rios; Miño y Dávila Editores, 2006. t. 3, p. 333-354.

Reissner, R. A. El indio en los diccionarios. Exégesis léxica de un estereotipo. México DF: Instituto Nacional Indigenista, 1983.

Sánchez VÁzquez, A. Ciencia y revolución. El marxismo de Althusser. México, DF: Grijalbo, 1986.

. Filosofía y circunstancias. Barcelona: Anthrophos, 1997.

Teobaldo, M.; Nicoletti, M. A. Entre centauros y santos: los indígenas de la Patagonia en los textos escolares oficiales y las biografías de Ceferino Namuncurá. In: Artieda, T. L. (Comp.). Los "otros" en los textos escolares: conflictos en la construcción de imágenes de nación. Luján: Universidad de Luján, 2009. p. 67-106.

VAn Dijк, T. A. Ideología. Una aproximación multidisciplinaria. Barcelona: Gedisa Editorial, 1999.

Voloshinov, V.N. Marxism and the philosophy of language. London: Harvard Press, 1986. Von Wright, G.H. Explanation and understanding. Ithaca,NY: Cornell University Press, 1971. WeLLs, G. Dialogic inquiry: towards a sociocultural practice and theory of education. Cambridge: Cambridge University Press, 1999.

\section{SOBRE LOS AUTORES}

Luis AjAgan Lester es doctor en pedagogía por la Universidad de Estocolmo (Suecia). Profesor del Instituto Mexicano de Estudios Pedagógicos (México). E-mail: luimar4930@gmail.com

Carlos Muñoz Labraña es doctor en pedagogía por la Universidad de Concepción (Chile). Profesor de la misma institución.

E-mail: carlosem@udec.cl

Recibido el 18 de mayo de 2017

Aprobado el 7 de diciembre de 2017

(C) 2018 Associação Nacional de Pós-Graduação e Pesquisa em Educação - ANPEd Este es un artículo de acceso abierto distribuido en términos de licencia Creative Commons. 